\title{
EPIDEMIOLOGIC PROFILE OF INITIAL COVID-19 PATIENTS AT A TERTIARY CARE CENTRE IN SOUTHERN RAJASTHAN
}

\begin{tabular}{ll} 
Dr Anjili Mathur & $\begin{array}{l}\text { Associate Professor, Dept of Community Medicine, RNT Medical College, } \\
\text { Udaipur }\end{array}$ \\
\hline $\begin{array}{l}\text { Dr Chandan } \\
\text { Fatehpuriya* }\end{array}$ & $\begin{array}{l}\text { Assistant Professor, Dept of Community Medicine, RNT Medical College, } \\
\text { Udaipur }{ }^{*} \text { Corresponding Author }\end{array}$ \\
\hline Dr Shikha Mehta & $\begin{array}{l}\text { Senior Demonstrator,Dept of Community Medicine, RNT Medical } \\
\text { College,Udaipur }\end{array}$ \\
\hline Dr Vipin Mathur & Senior Professor, Dept of Gastroenterology, RNT Medical College,Udaipur \\
\hline Dr Anum Fatima & $\begin{array}{l}\text { Resident Doctor,Dept of Community Medicine, RNT Medical College, } \\
\text { Udaipur }\end{array}$ \\
\hline $\begin{array}{l}\text { Dr Shruti } \\
\text { Priyadarshini }\end{array}$ & MBBS \\
\hline
\end{tabular}

ABSTRACT BACKGROUND: Amid the ongoing COVID-19 pandemic, we aimed to study its epidemiological and clinical characterstics OBJECTIVE: (1)To study epidemiological profile of first 100 covid cases admitted at DCH MB Hospital. (2)To study progression of disease among these covid-19 cases for 28 days.METHODOLOGY:This is observational cross sectional study of first hundred COVID-19 cases admitted at DCH, MB Hospital,Udaipur and followed up for 28 days.Data obtained from Case Investigation Form and indoor records.RESULT:Majority were males(60\%)Mean age was 35.88 years in males and 35.99 years in females. History of contact present in $62 \%$ and travel in $13 \% .41 \%$ were symptomatic and $14 \%$ had comorbidity.Recovery had no significant relation with gender,symptoms or comorbidity.Progression was good and CFR was $1 \%$.CONCLUSION: Recovery and progression was good among the patients, need to avoid travel and contact with others was noticed and people with comorbidities required to be more alert.

\section{KEYWORDS : Corona virus, COVID-19, rtPCR, Progression ,Rajasthan}

\section{INTRODUCTION:}

Coronavirus disease 2019 (COVID-19) was first recognized in Wuhan, China, in December 2019. WHO declared the outbreak a public health emergency of international concern on 30 January 2020 and on 11 March 2020, WHO declared COVID-19 as a pandemic. In India, the first case was reported on 30 January 2020 from the state of Kerala.l Coronavirus spreads mainly from person-to person by close contact (within about 6 feet) with infected people via respiratory source (coughs or sneezes) or by touching a surface or object on which virus is present.2 It primarily affects the respiratory system although other organ systems are also involved.3 Symptoms are nonspecific and disease presentation can range from no symptom to severe pneumonia and death. 1 In the absence of a licensed vaccine or effective therapeutics for COVID-19, non-pharmaceutical measures of hand hygiene and cough etiquettes and quarantine becomes a critical strategic containment and mitigation intervention towards the early detection and isolation of cases to break the chain of transmission. ${ }^{4}$

The present study is based on first hundred positive patients admitted at Maharana Bhupal Government Hospital(MBGH), which is a Dedicated Covid Hospital,located in Udaipur city, Rajasthan. Udaipur zone comprises of 6 districts namely Udaipur,Dungarpur,Banswara, Pratapgarh, Rajsamand and Chittorgarh.

\section{METHODOLOGY:}

STUDY DESIGN: This was a hospital based observational cross sectional study conducted over first 100 rtPCR confirmed covid-19 positive patients.

STUDY AREA: Study was conducted at Maharana Bhupal Hospital,Udaipur, a dedicated covid hospital,attached to RNT Medical College,Udaipur,Rajasthan.TOOLS AND
TECHNIQUE OF THE STUDY: The first 100 confirmed Covid19 cases of Udaipur zone admitted at MB Hospital,Udaipur were included in the study. A confirmed case is said to be one with laboratory confirmation of COVID-19 infection, irrespective of clinical signs and symptoms; which is done through nasopharyngeal and oropharyngeal swabs by real time Polymerase Chain Reaction (rtPCR) machine.l Information regarding epidemiological profile of patients was recorded from Case Investigation Form and follow-up of all these patients was done for 28 days for disease progression and outcome; for which indoor records were used after taking permission from the respective authority. Disease progress was measured on the basis of symptoms clinically, and whether the patient meanwhile required artificial oxygen or ventilator or the need to be shifted to ICU and by repeated rtPCR tests.

ANALYSIS OF DATA: Data collected was entered in personal computer .Appropriate tables were generated and analysed.

\section{RESULT:}

The first COVID-19 case of Udaipur zone was reported on 20 March 2020. Tests were conducted at Microbiology laboratory of RNT Medical College.All patients from Udaipur zone were admitted in corona block of MB Hospital.The first hundred patients who tested positive and were thereby admitted from 21 March 2020 to 30 April 2020 were included in the study. Figure 1 shows weekwise spread of COVID-19 in Udaipur zone.

Majority of cases (64\%) belonged to Banswara district followed by Chittorgarh (20\%), Udaipur(8\%), Dungarpur (5\%), Pratapgarh (2\%) and Rajsamand (1\%).

The mean age of these patients was 35.9 years (range of 2-84 years) with a male preponderance(60\%).It was observed that 
COVID-19 infection occurred in all age groups.Majority of patients belonged to the age group 21-30 years(22\%) followed by $41-50$ years (20\%).This may be related to limited travel by very young and elderly people and may not be related to susceptibility of these populations.A higher proportion of patients were males(60\%) as compared to females (40\%).In majority of age groups males were more in number except 0 10 years where female were more.[Figure 2]

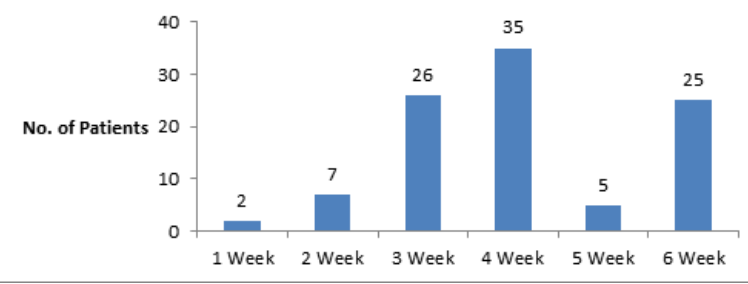

Figure 1: Weekwise spread of COVID-19 among first 100 patients of Udaipur zone.

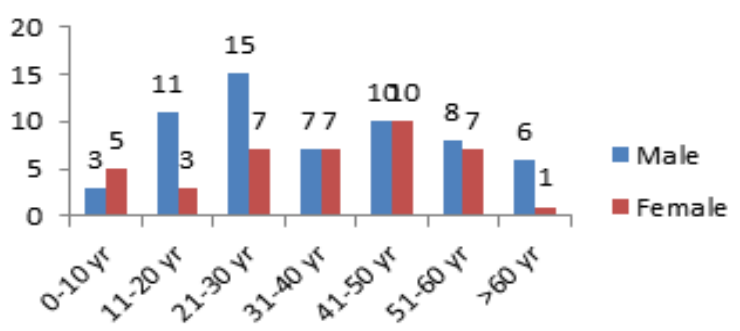

Figure 2 : Genderwise and agewise distribution

Contact history with COVID-19patients was present in 62\% and travel history to infected areas was present in $13 \%$ cases. Out of these 13, 1 reported international travel (Dubai), 7 reported interstate and 5 reported intrastate travel.

Clinical spectrum of COVID-19 patients is wide and variable ranging from asymptomatic infection to critical illness.In the present study most of the patients were asymptomatic (59\%). And among symptomatic patients(41\%), the most common symptoms reported were cough (48.7\%) ,fever (43.9\%).Some also presented with cold(19.5\%), sore throat(17\%),generalised weakness(9.7\%), shortness of breath(9.7\%), nausea $(7.3 \%)$ and diarrhoea $(4.8 \%)$.

Of all the patients, 14 (14\%) had comorbid conditions. Comorbidity refers to total burden of (chronic)illness other than the specific disease of interest. Major comorbid conditions were hypertension(64.2\%), diabetes mellitus type $2(21.4 \%)$, cardiovascular disease (21.4\%), hypothyroidism(14.2\%), uterus malignancy $(7.14 \%)$. One patient had a past history of myocardial infarction.

Of all the hundred patients followed for 28 days, 99 patients recovered ( 2 consecutive results of rtPCR were negative) and thereby discharged and l patient died.

Table 1: Average days to recover genderwise.

\begin{tabular}{|c|c|c|c|c|}
\hline S.No. & Days to Recover & Male & Female & Total \\
\hline 1 & $<7$ days & 1 & 2 & 3 \\
\hline 2 & $7-14$ & 30 & 16 & 46 \\
\hline 3 & $15-21$ & 21 & 15 & 36 \\
\hline 4 & $22-28$ & 6 & 5 & 11 \\
\hline 5 & $>28$ days & 1 & 2 & 3 \\
\hline & Total & 59 & 40 & 99 \\
\hline
\end{tabular}

Average days required to recover for male patients were 13.89 and female were 15.17.[Table 1] The difference in recovery of patients according to gender showed no significant result ( $p$ value $=0.29$ )
Table 2: Average days to recover according to presence or absence of symptoms

\begin{tabular}{|c|c|c|c|c|}
\hline S.No. & $\begin{array}{c}\text { Days to } \\
\text { Recover }\end{array}$ & $\begin{array}{c}\text { Symptoma } \\
\text { tic patients }\end{array}$ & $\begin{array}{c}\text { Asymptomatic } \\
\text { patients }\end{array}$ & Total \\
\hline 1 & $<7$ days & 2 & 2 & 4 \\
\hline 2 & $7-14$ & 14 & 32 & 46 \\
\hline 3 & $15-21$ & 15 & 20 & 35 \\
\hline 4 & $22-28$ & 8 & 3 & 11 \\
\hline 5 & $>28$ days & 1 & 2 & 3 \\
\hline & Total & 40 & 59 & 99 \\
\hline
\end{tabular}

Average days required to recover in patients with symptoms were 15.47 and without symptoms were 13.47.The p value was 0.29 which proves no significant difference.[Table 2]

Table 3: Average days to recover in patients with and without comorbidity

\begin{tabular}{|c|c|c|c|c|}
\hline S.No & Days to Recover & $\begin{array}{c}\text { With } \\
\text { Comorbidity }\end{array}$ & $\begin{array}{c}\text { Without } \\
\text { Comorbidity }\end{array}$ & Total \\
\hline 1 & $<7$ days & 1 & 2 & 3 \\
\hline 2 & $7-14$ & 5 & 41 & 46 \\
\hline 3 & $15-21$ & 4 & 32 & 36 \\
\hline 4 & $22-28$ & 2 & 9 & 11 \\
\hline 5 & $>28$ days & 1 & 2 & 3 \\
\hline & Total & 13 & 86 & 99 \\
\hline
\end{tabular}

And the average days required to recover in patients with comorbity were 13.92 and without cormorbidity were 14.9.The p value was 0.05 which proves no significant difference. [Table 3]

The case fatality rate among t hese 100 patients of COVID-19 was $1 \%$.This patient was a young adult, resident of Nimbaheda, Chittorgarh (a high risk area) with past history of inferior wall myocardial infarction and a recent travel history to Indore.He was admitted in ICU for 5 days before death.

None other patient required artificial oxygen,ventilator or were admitted to ICU.All have been discharged and none have reported any complaint or tested positive again since then.

\section{DISCUSSION}

A higher proportion of patients were males which is similar to a study in Taiwan5.More of a younger population (21-30 years) was involved in contrast to other studies of China6 which showed involvement of older population. Most patients were found to be asymptomatic which was comparable to this study of China6 and also in another study done in India by Nitesh Gupta et al.7 Among the symptomatic, the most common symptom reported in our study was cough followed by fever,which is similar to a study conducted by Bhandari et al in India. $^{8}$

CFR was less ( $1 \%$ ), similarly in a study of China 6 it was seen to be $3 \%$. Much less CFR (1\%) is observed as compared to other respiratory viral infections such as $\mathrm{HlNl}$, which had CFR of $9.7 \%$ in a study conducted in Rajasthan,India.9Also more involvement of males and adult age group is seen in both the infections.

\section{FUTURE SCOPE:}

At this period of time when conditions are worsening day by day and not much studies have been conducted especially in India our study aims to provide key insights into the epidemiology of SARS-CoV-2, thereby reducing the $\mathrm{R}$ ( reproductive number) of the cases.

\section{CONCLUSION}

Recovery and progression was good among the 
patients.Need to avoid travel and contact with others was noticed. And people with comorbidities required to be more alert so as to avoid acquiring the infection.

\section{REFERENCES:}

1. Joint statement of IPHA,IAPSM for containment plan. Published on April 11,2020. Available at: https://www.iphaonline.org/wp-content/ uploads/ 2020/04/Joint-Statement-of-IPHA IAPSM-for-COVID-19-containmentplan_April-11_6-pm_Final-1.pdf

2. Giao, Huynh, Nguyen \& Thi, Ngoc \& Thi Ngoc Han, Nguyen \& Khanh, Tran \& Ngan, Vo \& Tam, Vo \& Le An, Pham. (2020). Knowledge and attitude toward COVID-19 among healthcare workers at District 2 Hospital, Ho Chi Minh City. Asian Pacific Journal of Tropical Medicine. 13. 10.4103/1995-7645.280396.

3. Yuki K, Fujiogi M, Koutsogiannaki S.et al. COVID-19 pathophysiology: A review [published online ahead of print, 2020 Apr 20]. Clin Immunol. 2020;215:108427. doi:10.1016/j.clim.2020.108427

4. Mandal S, Bhatnagar T, Arinaminpathy N, et al. Prudent public health intervention strategies to control the coronavirus disease 2019 transmission in India: A mathematical model-based approach. Indian J Med Res. 2020;151(2 \& 3):190-199. doi:10.4103/ijmr.IJMR 504 20.

5. Cheng H, Jian S, Liu D, et al. Contact Tracing Assessment of COVID-19 Transmission Dynamics in Taiwan and Risk at Different Exposure Periods Before and After Symptom Onset. JAMA Intern Med. Published online May 01, 2020. doi:10.1001/jamainternmed.2020.2020

6. Bi Q, Wu Y, Mei S, Ye C, Zou X, Zhang Z, Liu X, Wei L, Truelove SA, Zhang T et al (2020) Epidemiology and transmission of COVID-19 in 391 cases and 1286 of their close contacts in Shenzhen, China: a retrospective cohort study. Lancet Infect Dis https://doi.org/10.1016/S1473-3099(20)30287-5

7. Nitesh Gupta et al.Clinical and epidemiologic profile of the initial COVID19 patients at a tertiary care centre in India.Monaldi Archieves for Chest disease; volume 90:1294.193-196

8. Bhandari et al. Clinical profile of COVID19 infected patients admitted in a tertiary care hospital in North India.JAPI May volume 68:13-17

9. Sharma, Chandra \& Keerti, \& Sharma, Shalabh \& Kumar, Arun \& Gupta, Manoj. (2012). Demographic correlates of swine flu cases attending a tertiary care hospital in Rajasthan. Indian journal of preventive and social medicine. 43. 224-228. 